\title{
Shubnikov-de Haas oscillations in diluted magnetic semiconductors $\left(\mathrm{Cd}_{1-\mathrm{x}-\mathrm{y}} \mathrm{Zn}_{\mathrm{x}} \mathrm{Mn}_{\mathrm{y}}\right)_{3} \mathrm{As}_{2}$
}

\author{
Vasilii S. Zakhvalinskii ${ }^{1}$, Tatyana B. Nikulicheva ${ }^{1}$, Erkki Lähderanta ${ }^{2}$, Aleksey $V$. Kochura $^{3,4}$, Ekaterina A. Nikitovskaia ${ }^{1}$, \\ Evgeny A. Pilyk ${ }^{1,4}$, and Mikhail A. Pogrebneak ${ }^{1}$ \\ ${ }^{1}$ Belgorod National Research University, 85 Pobedy St, Belgorod, 308015, Russia \\ ${ }^{2}$ Department of Mathematics and Physics, Lappeenranta University of Technology, \\ PO Box 20, FIN-53852 Lappeenranta, Finland \\ ${ }^{3}$ SouthWest State University, 9450 Let Oktjabrja str., Kursk, 305040, Russia \\ ${ }^{4}$ P.N. Lebedev Physical Institute of the RAS, 53 Leninskiyprosp., 119991, Moscow, Russia
}

\begin{abstract}
Single crystals of a diluted magnetic semiconductor $\left(\mathrm{Cd}_{1-\mathrm{x}-\mathrm{y}} \mathrm{Zn}_{\mathrm{x}} \mathrm{Mn}_{\mathrm{y}}\right)_{3} \mathrm{As}_{2} \quad(\mathrm{CZMA})$ $(x+y=0.4 ; y=0.04$ and 0.08$)$ obtained by Bridgman method were used. The Shubnikov-de Haas (SdH) effect was observed within studying of the dependence of the resistivity on the magnetic field in CZMA solid solutions. The values of the cyclotron mass $m_{\mathrm{c}}$, Hall and Shubnikov carrier concentrations were calculated.
\end{abstract}

\section{Introduction}

Diluted magnetic semiconductors (DMS) are the semiconductors in which a part of the cations is replaced by transition or rare-earth elements with partially filled d- or f-shells, respectively. These elements are randomly located in the semiconductor matrix, what leads to several types of interactions: the first, $s p-d$ ( $s p-f)$ exchange interaction between the band carriers and the localized magnetic moments of the atoms of transition (or rare-earth) elements; the second, $d-d(f-f)$ exchange interaction directly between the atoms of these elements.

The most known and studied DMS are Mn based solutions of semiconductors synthesized by different methods including crystallization from a melt and a molecular beam epitaxy [1, 2].At a sufficiently high concentration of magnetic ions, a ferromagnetic order appears in such DMS. Using materials with high Curie temperature $\left(T_{\mathrm{C}}\right)$ extends the capabilities of modern microelectronics and gives an impetus to develop spintronics [3]. By now, DMS structures with $T_{\mathrm{C}} \sim 200 \mathrm{~K}$ based on $p-\left(\mathrm{Ga}_{1-x} \mathrm{Mn}_{x}\right)$ As have been obtained [4]. In some materials such as $p-(\mathrm{Ga}, \mathrm{Mn}) \mathrm{P}, \quad p$ - and $n$ $(\mathrm{Ga}, \mathrm{Mn}) \mathrm{N}$, ferromagnetism was also detected at temperatures exceeding the room temperature [5].

On the other hand, a group of DMS based on the 3D Dirac semimetal $\mathrm{Cd}_{3} \mathrm{As}_{2}$ [6] is of particular interest. Recently evidences of an existence of a topological states in $\left(\mathrm{Cd}_{1-\mathrm{x}} \mathrm{Zn}_{\mathrm{x}}\right) \mathrm{As}_{2}$ solid solutions have been observed $[7,8]$. The research of magnetic solid solutions based on $\mathrm{Cd}_{3} \mathrm{As}_{2}$ allowsusto trace the evolution of topological properties and will create prerequisites for a practical application of this unique material. The purpose of this article was to investigate the properties of solid solutions of a diluted magnetic semiconductor $\left(\mathrm{Cd}_{1-\mathrm{x}-\mathrm{y}} \mathrm{Zn}_{\mathrm{x}} \mathrm{Mn}_{\mathrm{y}}\right)_{3} \mathrm{As}_{2}$.

\section{Experimental details, results and discussion}

A modified Bridgeman method was used to obtain single crystals of $\left(\mathrm{Cd}_{1-\mathrm{x}-\mathrm{y}} \mathrm{Zn}_{\mathrm{x}} \mathrm{Mn}_{\mathrm{y}}\right)_{3} \mathrm{As}_{2} \quad$ (CZMA) $\quad(x+y=0.4$; $y=0.04$ and 0.08 ). The composition and homogeneity of the samples were analyzed by X-ray powder diffraction and energy-dispersive X-ray spectroscopy (EDX) methods. All the investigated samples $\left(\mathrm{Cd}_{1-\mathrm{x}-}\right.$ $\left.{ }_{\mathrm{y}} \mathrm{Zn}_{\mathrm{x}} \mathrm{Mn}_{\mathrm{y}}\right)_{3} \mathrm{As}_{2}$ had a tetragonal crystal system $(\alpha "-$ $\mathrm{Cd}_{3} \mathrm{As}_{2}$ ), space group $\mathrm{P} 4_{2} / \mathrm{nmc}$ [9].

The Shubnikov-de Haas ( $\mathrm{SdH})$ effect was observed within studying the dependence of the resistivity on the magnetic field in CZMA solid solutions. Measurements were made on the pulsed magnetic field facility in the temperature range from $1.6 \mathrm{~K}$ to $300 \mathrm{~K}$ and the magnetic fields from 0 to $25 \mathrm{~T}$. The $\mathrm{SdH}$ oscillations observed in the CZMA samples are shown in Figure.

Increasing of an amplitude of the $\mathrm{SdH}$ oscillations in the investigated samples $\left(\mathrm{Cd}_{0.6} \mathrm{Zn}_{0.36} \mathrm{Mn}_{0.04}\right)_{3} \mathrm{As}_{2}$ and $\left(\mathrm{Cd}_{0.6} \mathrm{Zn}_{0.32} \mathrm{Mn}_{0.08}\right)_{3} \mathrm{As}_{2}$ with at increasing a magnetic field is similar to that observed earlier for other CZMA compositions $[10,11]$.

The amplitude of the SdH oscillations can be written as [2]:

$$
A \sim B^{-1 / 2} z / \operatorname{sh}(z) \exp \left[-2 \pi^{2} m_{c} k_{B} T_{D} /(\eta e B)\right] \cos (\pi v)
$$

\footnotetext{
Corresponding author: zakhvalinskii@bsu.edu.ru
} 
where $z=2 \pi^{2} m_{c} k_{B} T /(\eta e B), \quad T_{D} \quad$ is the Dingle temperature, $v=g m_{c} /\left(2 m_{0}\right), m_{c}$ is the cyclotron mass, $m_{0}$, $\hbar, e$ and $k_{B}$ are the physical constant.

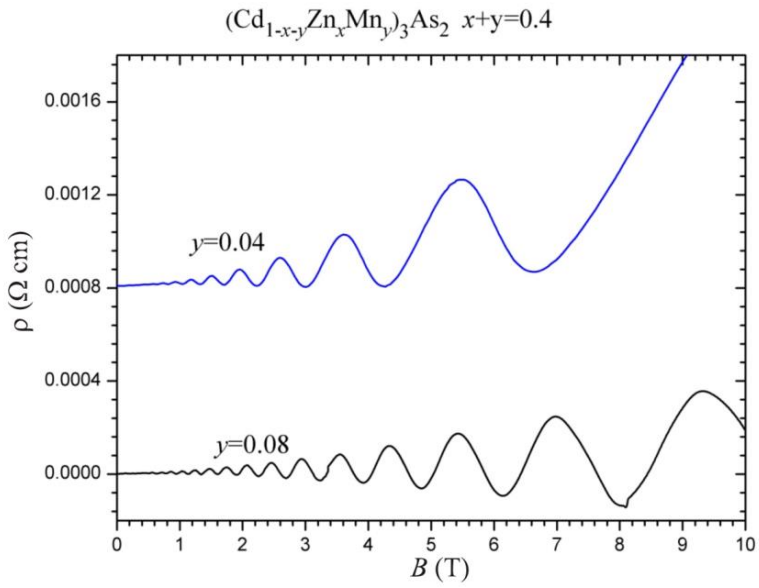

Figure. Shubnikov-de Haas oscillations in single crystals $\left(\mathrm{Cd}_{1-\mathrm{x}-\mathrm{y}} \mathrm{Zn}_{\mathrm{x}} \mathrm{Mn}_{\mathrm{y}}\right)_{3} \mathrm{As}_{2}(x+y=0.4 ; y=0.04$ and 0.08 at $T=2.4 \mathrm{~K})$.

According to the results of [10], in our samples the gfactor should not depend on a temperature. So, an analysis of the amplitudes of the Shubnikov-de Haas oscillations using Eq. (1) and the values of the $\mathrm{SdH}$ amplitudes measured at two different temperatures at a fixed value of the magnetic field, as in conventional semiconductors, makes it possible to determine a number of parameters, for example, the cyclotron mass [9].The comparison of charge carrier concentrations obtained from Hall and Shubnikov measurements was carried out (Table). The Hall carrier concentration was calculated as follows [13]:

$$
n_{\mathrm{R}}=1 /\left(e R_{\mathrm{H}}\right)
$$

where $n_{\mathrm{R}}$ is the concentration of charge carriers, $e$ is electron charge and $R_{\mathrm{H}}$ is Hall coefficient.

Table. Parameters found from the $\mathrm{SdH}$ oscillations of CZMA samples $(x+y=0.4 ; y=0.04$ and 0.08$)$ and for undoped $\mathrm{Cd}_{3} \mathrm{As}_{2}[15,16]$.

\begin{tabular}{|l|l|l|l|}
\hline$y(\mathrm{Mn})$ & 0.04 & 0.08 & $\mathrm{Cd}_{3} \mathrm{As}_{2}$ \\
\hline$n_{\mathrm{R}} / n_{\mathrm{SdH}}$ & 0.97 & 1.04 & $1.2[15]$ \\
\hline$\mu_{\mathrm{H}} \cdot 10^{-4}, \mathrm{~cm}^{2} \mathrm{~V}^{-1} \mathrm{~s}^{-1}$ & 2.28 & 1.53 & $2.9[16]$ \\
\hline$P_{S d H}, \mathrm{~T}^{-1}$ & 0.061 & 0.025 & $0.02[16]$ \\
\hline$m_{\mathrm{c}}(0) / m_{0}$ & 0.0409 & 0.0435 & $0.043[16]$ \\
\hline
\end{tabular}

Shubnikov carrier concentration was calculated according to the equation [14]:

$$
n_{S d H}=\frac{1}{3} \pi^{2}\left(\frac{2 e}{\eta P_{S d H}}\right)^{3 / 2}
$$

where $P_{S d H}$ is the period of the $\mathrm{SdH}$ oscillations, the ratio $n_{\mathrm{R}} / n_{\mathrm{SdH}}$ is close to unity, in accordance with results obtained previously for CZMA $[10,11,13]$. When considering the properties of solid solutions of $\left(\mathrm{Cd}_{1-\mathrm{x}-}\right.$ $\left.{ }_{\mathrm{y}} \mathrm{Zn}_{\mathrm{x}} \mathrm{Mn}_{\mathrm{y}}\right)_{3} \mathrm{As}_{2}$, we were based on the similarity of the band structure of $\mathrm{Cd}_{3} \mathrm{As}_{2}$ and $\mathrm{InSb}$ [16].

\section{Conclusions}

In this paper we performed an investigation of the Shubnikov de Haas effect in single crystals of solid solutions of diluted magnetic semiconductors $\mathrm{Cd}_{1-\mathrm{x}-}$ $\left.{ }_{\mathrm{y}} \mathrm{Zn}_{\mathrm{x}} \mathrm{Mn}_{\mathrm{y}}\right)_{3} \mathrm{As}_{2}(x+y=0.4 ; y=0.04$ and 0.08$)$, obtained by Bridgman method based on 3D Dirac semimetals $\mathrm{Cd}_{3} \mathrm{As}_{2}$. For both samples the value of the cyclotron effective mass of charge carriers $m_{\mathrm{c}}$, Shubnikov $n_{\mathrm{SdH}}$ and Hall $n_{\mathrm{R}}$ concentration, mobility, $\mu_{\mathrm{H}}$, of charge carriers and period of oscillations $P_{\mathrm{SdH}}$, were defined (Table). The obtained parameters do not conflict with similar results obtained previously for diluted magnetic semiconductors CZMA $(x+y=0.2 ; x+y=0.3)[10,11$, $13]$.

This work was supported by the Russian Science Foundation (grant №17-12-01345) in the part of crystal growth and structure characterization.

\section{References}

1. J. Cisowski.Phys. Stat. Sol. B200, 311 (1997).

2. J. K. Furdyna and J. Kossut.Diluted Magnetic Semiconductors, (Ed.Semicond. AndSemimet., Vol. 25, Academic Press, Boston, 1988).

3. I.Zutic, J.Fabian, S.D.Sarma.Reviews of Modern Physics 76, 2, 323 (2004).

4. L.Chen, X.Yang, F.Yang, J.Zhao, J.Misuraca,P.Xiong, S.von Molnar.Nano.Lett. 11, 2584(2011).

5. K.A. Kikoin and V.N. Fleurov.Transition Metal Impurities in Semiconductors(WorldScientific, Singapore, 1994).

6. Z. Wang, H. Weng, Q. Wu, X. Dai, Z. Fang.Phys. Rev. B88,125427(2013).

7. A.V. Galeeva, I.V. Krylov, K.A. Drozdov, A.F. Knjazev, A.V. Kochura, A.P. Kuzmenko, V.S. Zakhvalinskii, S.N. Danilov, L.I. Ryabova, D.R. Khokhlov. Beilstain J. Nanotechnol. 8, 167 (2017).

8. H. Lu, X. Zhang, Y. Bian, Sh. Jia. Scientific Reports 7, 3148 (2017).

9. ICSD Database, Version 2009-1, Ref. code 23245.

10. R.Laiho, K.G.Lisunov, V.N.Stamovand V.S. Zahvalinskii.J. Phys. Chem. Solids57, 1, 1, (1996).

11. R.Laiho, E.Lahderanta,K.G.Lisunov, V.N. Stamov and V.S. Zahvalinskii. J. Phys. Chem. Solids. 58, 5, 717 (1997).

12. I.M. Tsidilkovsky.Electrons and Holes in Semiconductors,(Nauka, Moscow,1972).

13. R.Laiho, K.G.Lisunov, M.L. Shubnikov, V.N.Stamovand V.S. Zahvalinskii.Phys. Stat. Sol. B198, 135(1996).

14. B.I. Shklovskii and A.L Efros. Electronic Properties of Doped Semiconductors, Springer-Verlag, Berlin (1984).

15. .M. Tsidilkovsky. Gapless semiconductors - a New Class of Materials, Academie, Berlin (1988).

16. E.O. Kane. Band structure of indium antimonide. J. Phys. Chem. Sol. 1, 249 (1957). 